\title{
Mifepristone versus intracervical prostaglandin E2 gel for cervical ripening in primigravid patients at term
}

\author{
Manoj Kumar Sah ${ }^{1 *}$, Saraswati M. Padhye ${ }^{2}$
}

\begin{abstract}
${ }^{1}$ Department of Obstetrics and Gynecology, B. P. Koirala Institute of Health Sciences, Dharan, Nepal
${ }^{2}$ Department of Obstetrics and Gynecology, Kathmandu Medical College Teaching Hospital, Kathmandu, Nepal
\end{abstract}

Received: 22 January 2018

Accepted: 14 February 2018

\author{
*Correspondence: \\ Dr. Manoj Kumar Sah, \\ E-mail:drgmanoj@gmail.com
}

Copyright: (C) the author(s), publisher and licensee Medip Academy. This is an open-access article distributed under the terms of the Creative Commons Attribution Non-Commercial License, which permits unrestricted non-commercial use, distribution, and reproduction in any medium, provided the original work is properly cited.

\begin{abstract}
Background: The cervix has to play dual role in human reproduction. During pregnancy, it should remain firm and closed allowing the fetus to grow in utero until functional maturity is attained while during labour it should soften and dilate, allowing the fetus to pass through the birth canal. Objective of present study was to know and compare the effect of oral Mifepristone with intracervical dinoprostone gel for cervical priming prior to induction of labour at term in an unfavorable cervix of primigravida.

Methods: This was prospective randomized comparative study. 100 primigravid patients were included, 50 were placed in each group A and B. Tablet Mifepristone $200 \mathrm{mg}$ orally was given in group A patients and intracervical dinoprostone gel induction was done in group B patients. Pre induction Bishop's score was noted at beginning to compare improvement in Bishop's score after induction. Mode of delivery and induction to delivery interval in both the groups were studied.

Results: After induction with Mifepristone $76 \%$ women had successful cervical ripening as compared to $56 \%$ with dinoprostone. Rate of vaginal delivery was $70 \%$ with Mifepristone and $58 \%$ with dinoprostone. There was no significant difference in induction to delivery interval between the groups. Ten percent and $2 \%$ belonging to mifepristone and dinoprostone group respectively, required NICU admissions.

Conclusions: Mifepristone is more effective than dinoprostone for preinduction cervical ripening as it has high success rate of achieving cervical ripening, however there is no significant difference in the vaginal delivery rate and other maternal and fetal outcome.
\end{abstract}

Keywords: Cervical ripening, Dinoprostone, Induction, Mifepristone

\section{INTRODUCTION}

The cervix has to play dual role in human reproduction. During pregnancy, it should remain firm and closed allowing the fetus to grow in utero until functional maturity is attained while during labour it should soften and dilate, allowing the fetus to pass through the birth canal. The process by which the cervix becomes soft, compliant and partially dilated is termed "cervical ripening." Cervical ripening is thought to be due to combination of biochemical, endocrinal, mechanical, and possibly inflammatory events. Cervical ripening allows the uterine contractions to effectively dilate the cervix.

The goal of cervical ripening is to facilitate the process of cervical softening, effacement and dilatation, thus reducing the induction-to-delivery time. When there is an indication for induction and the cervix in unfavorable, agents for cervical ripening may be used. ${ }^{1}$

The two major techniques for iatrogenic cervical ripening are 
- Mechanical interventions, such as insertion of catheters or cervical dilators, and

- Pharmacological such as application of cervical ripening agents (prostaglandins).

Induction of labour is carried out in over $20 \%$ of pregnancies on an average in developed countries. It is indicated to be advantageous for both the mother and baby, decrease perinatal morbidity and mortality. Induction between $37-41$ weeks has the potential to improve neonatal outcomes. However, it is associated with a doubling in the caesarean delivery rate compared with spontaneous labour.

Successful labour induction is related to state of the cervix. Pregnant lady with unfavorable cervix, who have not experienced cervical ripening phase prior to labour, present a great challenge with regard to induction of labour. So, Bishop's scoring is done to see whether the cervix is favorable or not. If induction is done in an unfavorable cervix, chances of prolonged labour and chances of having cesarean section will be increased. To reduce cesarean section rate cervical ripening is done prior to induction

Local application of prostaglandin E2 - dinoprostone - is commonly used for cervical ripening. ${ }^{2}$

Mifepristone /RU-(486), a new class of pharmacological agents (antiprogestins) have been developed to antagonize the action of progesterone. Mifepristone is use for inducing labour in late pregnancy by antagonizing progesterone, thus increasing uterine contractility and by increasing the sensitivity of the uterus to the actions of prostaglandins. ${ }^{3}$

Prevention of progestogenic effect by Mifepristone promotes cervical ripening owing to the action of estrogens, such as increase in cervical collagenase and prostaglandin synthetize activity, enhance expression of the extracellular matrix degrading protease stromelysin$1.4,5$

The most commonly used approved indications for Mifepristone in obstetrics include: termination of early pregnancy, cervical dilatation prior to surgical abortion, labour induction in case of fetal death in utero. Fewer studies have been conducted on the effect of Mifepristone on cervical ripening and induction of labour in term pregnancy with a live fetus. ${ }^{6}$

More recent studies showed improvement in cervical score within 24-48 h, decline the cesarean rate, amount of dose requirement of augmentation of labour, lesser NICU admission and maternal complication after mifepristone induction in term and prolonged pregnancy. ${ }^{7}$ There is report of the use of Mifepristone for induction of labour in women with previous cesarean section. ${ }^{8}$ Therefore, it is still of interest to continue studies, which will help to evaluate efficacy and safety of mifepristone for labor induction in full-term pregnancy.

This study was carried out to know and compare the effect of oral Mifepristone with intracervical dinoprostone gel for cervical priming prior to induction of labour at term in an unfavorable cervix of primigravida.

Objective of present study were to study the changes and compare cervical score among patient receiving mifepristone and dinoprostone e, to compare the induction to delivery time interval between the two groups, to know and compare the mode of delivery and maternal complication among two groups and to observe the fetal outcome among two groups in terms of, $1 \mathrm{~min}$ and 5 min Apgar score and need of NICU admission.

\section{METHODS}

This was Prospective randomized comparative study conducted at the department of Obstetrics and Gynecology of Kathmandu Medical College Teaching Hospital. Total duration of study was 9 months. From November 2013 to August 2014. The study was done in 100 primigravida. Following Inclusion and exclusion criteria were used.

\section{Inclusion criteria}

- Primigravida with singleton pregnancy at term pregnancy (37-42 weeks confirmed by date and early ultrasound if dates are not sure) in Cephalic presentation

- $\quad$ Bishop's score $\leq 5$

- Intact Membrane

- Reactive fetal heart rate pattern in CTG

- Consenting to participate.

\section{Exclusion criteria}

- Cephalopelvic disproportion on clinical pelvimetry

- Renal, hepatic or cardiovascular disease and severe asthma

- Medical condition which contraindicates the use of mifepristone example: adrenal insufficiency, hemorrhagic disorders, inherited porphyria, and ladies on anticoagulant or long term corticosteroids

- Hypersensitivity to both drugs

- Prior uterine scar (previous cesarean section or myomectomy)

- Those candidates who do not want to take part in the study.

Patients selected as per the inclusion criteria and exclusion criteria. After obtaining informed consent, a detailed history was taken, complete physical examination and Bishop score assessment was done. Routine investigations were done for all patients. 
Then the candidates were asked to pick a chit from a box containing 100 chits, labeled as ' $\mathrm{M}$ ' on 50 and ' $\mathrm{D}$ ' on other 50. These chits were folded to conceal labeling. Out of 100 , fifty pregnant lady who will picks ' $\mathrm{M}$ ' chits received $200 \mathrm{mg}$ oral Mifepristone (Group A) and next fifty who picked ' $\mathrm{D}$ ' chit received intracervical dinoprostone gel $0.5 \mathrm{mg}$ (Group B).

So, the patients of group A received tablet Mifepristone $200 \mathrm{mg}$ orally and patient was examined every one hourly for uterine contraction and FHR. If patient begin to get adequate contraction, PV examination was done to see change in Bishop`s score. Once Bishop`s score was favorable, patient was augmented with Oxytocin as per hospital protocol. The active stage of labour was monitored using Partograph. Uterine contraction and fetal heart sound were monitored every half an hour. Pelvic assessment of pregnant lady was done every 4 hourly till delivery, and if patient did not get contraction then patient was examined 24 hours after the intake of Mifepristone to see change in the Bishop's score and then patient was induced with Oxytocin irrespective of the Bishop`s score.

Patients of group B were instilled with intracervical dinoprostone gel with all aseptic precaution. Pregnant ladies were asked to lie in left lateral position for 30 minutes and after application. Fetal heart sound was checked immediately. They were evaluated one hourly for fetal heart rate and uterine contraction. Pelvic examination for Bishop's score was done after 8 hours and if the cervix was still unfavourable, second dose of dinoprostone gel was installed. Cervix was considered favourable if Bishop score was 6 or more than 6 . Induction of labour with Oxytocin in titration dose was given intravenously 24 hours after first dose even if the cervix is unfavourable. If rupture of membrane occurs, induction with Oxytocin was started after 6 hours of last dose of dinoprostone gel. If the pregnant lady goes into active stage labour, Partograph was maintained. Uterine contraction and fetal heart sound was monitored every half an hour. Pelvic assessment of pregnant lady was done every 4 hourly till delivery.

\section{Statistical analysis}

Data was entered in Excel spreadsheet as master chart and was analysed using SPSS version 20. T test and chi square test was used for data analysis.

\section{RESULTS}

The demographic details of women of both groups are presented in Table 1 There was not significant difference in the age of the patients and mean gestational age among two groups.

Table 1: Demographic data.

\begin{tabular}{|c|c|c|c|c|}
\hline Age in years & Mifepristone ( $\mathrm{n}=\mathbf{5 0}$ ) & Dinoprostone $(\mathrm{n}=\mathbf{5 0})$ & Total $(n=100)$ & P value \\
\hline$<20$ & 5 & 3 & $8(8 \%)$ & \multirow{6}{*}{0.356} \\
\hline $20-24$ & 28 & 26 & $54(54 \%)$ & \\
\hline $25-29$ & 10 & 16 & $16(16 \%)$ & \\
\hline $30-34$ & 6 & 5 & $11(11 \%)$ & \\
\hline$>35$ & 1 & 0 & $1(1 \%)$ & \\
\hline Mean age $( \pm \mathrm{SD})$ & $23.90( \pm 3.99)$ & $24.58( \pm 3.50)$ & & \\
\hline Mean gestation age $( \pm \mathrm{SD})$ & $40.18( \pm 1.01)$ & $39.79( \pm 1.74)$ & & 0.182 \\
\hline
\end{tabular}

Table 2: Change in Bishop`s score.

\begin{tabular}{|llll|}
\hline $\begin{array}{l}\text { Initial Bishop } \\
\text { score, mean } \\
( \pm \mathrm{SD})\end{array}$ & $3.58( \pm 0.60)$ & $3.40( \pm 0.49)$ & 0.108 \\
$\begin{array}{l}\text { Change in } \\
\begin{array}{l}\text { Bishop score } \\
\text { after 24 hours } \\
\text { mean }( \pm \mathrm{SD})\end{array}\end{array}$ & $6.40( \pm 1.64)$ & $5.26( \pm 1.85)$ & 0.002 \\
\hline
\end{tabular}

There was no significant difference in pre induction Bishop score in two groups. Post induction Bishop score was significantly better in Mifepristone group compared to dinoprostone group $(\mathrm{P}=0.002)$ as shown in Table 2 .
Table 3: Success rate.

\begin{tabular}{|llll|}
\hline & $\begin{array}{l}\text { Mifepristone } \\
(\mathrm{n}=50)\end{array}$ & $\begin{array}{l}\text { Dinoprostone } \\
(\mathrm{n}=50)\end{array}$ & $\begin{array}{l}\mathrm{P} \\
\text { value }\end{array}$ \\
\hline $\begin{array}{l}\text { Successful } \\
\text { priming }\end{array}$ & $38(76 \%)$ & $28(56 \%)$ & \\
\hline $\begin{array}{l}\text { Unsuccessful } \\
\text { priming }\end{array}$ & $12(24 \%)$ & $22(44 \%)$ & 0.001 \\
\hline
\end{tabular}

Success was taken as improvement of Bishop score $\geq 6$ after 24 hours of intake of mifepristone in mifepristone group and 24 hours after the first dose of dinoprostone in dinoprostone group Success rate was $76 \%$ in mifepristone group and $56 \%$ in dinoprostone group. This difference was statistically significant $(\mathrm{p}<0.001)$ (Table 3). 
Table 4: Mode of delivery.

\begin{tabular}{|lllc|}
\hline & $\begin{array}{l}\text { Mifepristone } \\
(\mathrm{n}=50)\end{array}$ & $\begin{array}{l}\text { Dinoprostone } \\
(\mathrm{n}=50)\end{array}$ & Total \\
\hline $\begin{array}{l}\text { Emergency } \\
\text { LSCS }\end{array}$ & $15(30 \%)$ & $16(32 \%)$ & 31 \\
\hline $\begin{array}{l}\text { Vaginal } \\
\text { delivery }\end{array}$ & $30(60 \%)$ & $29(85 \%)$ & 59 \\
$\begin{array}{l}\text { Instrumental } \\
\text { vaginal } \\
\text { delivery* }\end{array}$ & $5(10 \%)$ & $5(10 \%)$ & 10 \\
**all vacuum delivery, $\mathrm{P}=0.49$ & & \\
\hline
\end{tabular}

In mifeprisotone group $35(70 \%)$ patients has vaginal delivery and $15(30 \%)$ had caesarean section. In dinoprostone group $34(58 \%)$ patients had vaginal delivery and $16(32 \%)$ patients had caesarean section. The difference was not statistically significant $(\mathrm{p}=0.49)$ (Table 4).

Table 5: Induction to delivery interval.

\begin{tabular}{llll}
$\begin{array}{llll}\text { Induction to } \\
\text { delivery }\end{array}$ & Mifepristone & Dinoprostone & $\begin{array}{l}\text { P } \\
\text { value }\end{array}$ \\
time, & 39.06 & 41.30 & 0.493 \\
mean $( \pm$ SD $)$ & $( \pm 15.00)$ & $( \pm 17.41)$ & \\
\hline
\end{tabular}

The mean $( \pm \mathrm{SD})$ induction to delivery interval in Mifepristone group was $39.06( \pm 15.00)$ hours and in dinoprostone group it was $41.30( \pm 17.41)$. There was no significant difference in both the groups $(\mathrm{P}=0.493)$ (Table $5)$.

Table 6: Neonatal outcome.

\begin{tabular}{|lll|l|}
\hline & Mifepristone & Dinoprostone & $\begin{array}{l}\text { P } \\
\text { value }\end{array}$ \\
\hline $\begin{array}{l}\text { Apgar score } \\
\text { at } 1 \mathrm{~min} \\
\text { (mean } \pm \text { SD) }\end{array}$ & $6.86 \pm 0.49$ & $6.94 \pm 0.31$ & 0.337 \\
\hline $\begin{array}{l}\text { Apgar score } \\
\text { at } 5 \mathrm{~min} \\
\text { (mean } \pm \text { SD) }\end{array}$ & $7.78 \pm 0.67$ & $8.00 \pm 00$ & 0.220 \\
\hline $\begin{array}{l}\text { NICU } \\
\text { admission }\end{array}$ & $5(10 \%)$ & $1(2 \%)$ & 0.069 \\
\hline
\end{tabular}

Five Neonates in Mifepristone group one neonate in dinoprostone group needed admission in NICU due to birth asphyxia. However, there was no significant difference in NICU admission rate and Apgar score in 1 and 5 minutes between two groups (Table 6).

One patient from mifepristone group had Post partum haemorrhage and one patient from dinoprostone group had urinary retention.

\section{DISCUSSION}

In this study it was found that Bishops score was improved more in Mifepristone group compared to dinoprostone group $(\mathrm{p}=0.002)$. Baev $\mathrm{O}$ compared 2 doses of Mifepristone $200 \mathrm{mg}$ tablet per oral at interval of 24 hours and 3 doses of intracervial dinoprostone at interval of 6 hours also found that Bishops score improved more in Mifepristone group compared to dinoprostone group $(\mathrm{p}=0.02) .{ }^{9}$ Gaikwad V et al, compared Single dose of Tab Mifepristone with single dose of Dinoprostone. ${ }^{10}$ They found significant improvement in Bishop's score in Mifepristone induced group than dinoprostone group.

The success rate of priming in mifepristone group was 76 $\%$ and $56 \%$ in dinoprostone group. It was consistent with finding of Gaikwad V et al, in their study success rate of mifepristone was $96.6 \%$ and success rate of dinoprostone was $76.6 \% .^{10}$

Induction to delivery interval was shorted in Mifepristone group compared to dinoprostone group. The mean duration in mifepristone group was $39.06( \pm 15.00)$ hours and in dinoprostone group was $41.30( \pm 17.41)$ hours, however the difference was not significant. Shanitha Fathima et al, found significant difference in induction to delivery interval among two groups $(p=0.001) .{ }^{11}$ In Mifepristone group mean duration was 32.00 hours and in dinoprostone group it was only 18.17 hours. Gaikwad $\mathrm{V}$ et al also had similar result. ${ }^{10}$ Induction to delivery interval in mifperistone group was $29.2( \pm 15.1)$ and in dinoprostone group was $21.4( \pm 10.1)$. The result was significantly different $(\mathrm{p}<0.005)$

Rate of LSCS in mifepristone group in this study was $30 \%$, where as in dinoprostone group it was $32 \%$. It was not statistically significant $(\mathrm{P}=0.49)$. Similar findings were noted by Shanitha $\mathrm{F}$ et al. ${ }^{11}$ Gaikwad V et al also found high rate of LSCS in dinoprostone group. ${ }^{10}$ In their study $16 \%$ rate of LSCS was in mifepristone group and $44 \%$ in dinoprostone group. They found significant difference in rate of LSCS amongs two groups $(\mathrm{P}=0.001)$.

In this study the most common indication for LSCS was fetal distress, it was $73.33 \%$ in Mifepristone group and $62.5 \%$ in dinoprostone group. Fetal distress was also the most common indication for LSCS in the study of Fathima Shanitha et al. ${ }^{11}$ Gaikwad V et al in their study found that the most common indication for LSCS was fetal distress in Mifepristone group (8\%) and the most common indication for LSCS was failed induction in dinoprostone group (28\%). ${ }^{10}$

In this study fetal outcome shows no significant difference between two groups with respect to birth weight, and Apgar score at 1 minutes and 5 minutes.

Five neonate (10\%) required NICU admission in Mifepristone group and one $(2 \%)$ cases required NICU admission in dinoprostone group. There were no significant association in NICU admission $(\mathrm{p}=0.069)$ among two groups. Gaikwad V et al found more NICU admission in dinoprostone group (14\%) compared to Mifepristone group (6\%). ${ }^{10}$ 


\section{CONCLUSION}

Mifepristone is more effective than dinoprostone for pre induction cervical ripening as it has high success rate of achieving cervical ripening, however there is no significant difference in the vaginal delivery rate and other maternal and fetal outcome.

\section{ACKNOWLEDGMENT}

Authors would like to thank the patients who took part in this study.

Funding: No funding sources

Conflict of interest: None declared

Ethical approval: The study was approved by the Institutional Ethics Committee

\section{REFERENCES}

1. Sabaratnam A, Gita A, Leonie PK. The management of labour. $3^{\text {rd }}$ Ed. India: university press (India) private Limited;2011:1-14.

2. Athawale R, Acharya N, Samal S, Hariharan C. Effect of mifepristone in cervical ripening for induction of labour. Int J Reprod Contracept Obstet Gynecol 2013;2:35-8.

3. Hapangama D, Neilson JP. Mifepristone for induction of labour. Cochrane Database Syst Rev. 2009;(3): CD002865.

4. Gupta J, Johnson N. Effect of mifepristone on dilatation of the pregnant and non-pregnant cervix. Lancet. 1990;335(8700):1238-40.

5. Schatz F, Papp C, Aigner S, Krikun G, Hausknecht V, Lockwood CJ. Biological underlying the clinical effects of RU 486: modulation of cultured endometrial stromal cell stromelysin-1 and prolactin expression. J Clin Endocrinol Metab. 1997;82(1):188-93.

6. Baev OR, Rumyantseva VP, Tysyachnyu OV, Kozlova OA, Sukhikh GT. Outcomes of mifepristone usage for cervical ripening and induction of labour in full-term pregnancy. Randomized controlled trial. Eur J Obstet Gynecol Reprod Biol. 2017 Oct;217:144-9.

7. Yelikar K, Deshpande S, Deshpande R, Lone D. Safety and efficacy of oral mifepristone in preinduction cervical ripening and induction of labour in prolonged pregnancy. J Obstet Gynaecol India. 2015;65(4):221-5.

8. Sharma CH, Soni A, Soni PK, Verma S, Verma A, Gupta A. A retrospective case-control study evaluating the role of mifepristone for induction of labor in women with previous cesarean section. $\mathbf{J}$ Obstet Gynecol India 2016;66(S1):30-7.

9. Baev O, Rumyantseva V. Mifepristone versus intracervical prostaglandin E2 gel for cervical ripening and labor induction. Geburtshilfe Frauenheilkd. 2011;71:A33.

10. Gaikwad V, Mittal B, Mangal P. Comparative analysis of safety, efficacy and feto maternal outcome of induction of labour with mifepristone versus intracervical dinoprostone gel. RJPBCS. 2014;5(2):611.

11. Shanitha F, Nayak SR, Rao B, Gandhi P, Shameem VPA. Mifepristone in the induction of labour at term. Int J Pharm Biomed Res. 2013;4(3):164-6.

Cite this article as: Sah MK, Padhye SM.

Mifepristone versus intracervical prostaglandin E2 gel for cervical ripening in primigravid patients at term. Int J Reprod Contracept Obstet Gynecol 2018;7:824-8. 